\title{
PERCURSOS DE AUTORIA E SUBJETIVAÇÃO: entre rodas, rimas e clipes
}

\author{
Valentina Carranza Weihmüllerl \\ Andréa Costa da Silva² \\ Vera Helena Ferraz de Siqueira ${ }^{3}$
}

\section{RESUMO}

Neste artigo analisamos a construção de autoria e processos de subjetivação por um coletivo de hip hop que organiza rodas culturais, no complexo de favelas de Manguinhos, Rio de Janeiro. As rodas culturais são iniciativas de caráter público, ligadas ao movimento hip hop e de recente surgimento na cena carioca. Com esse cenário, buscamos entender tais eventos e textos, em sua modalidade ao vivo, bem como nas mídias digitais. Compreendemos as rodas como instâncias culturais geradoras de processos de subjetivação e posições de sujeito, em suas dimensões: política, pedagógica, identitária e simbólica. Com base nos estudos culturais em sua vertente pós-estruturalista, assumimos as rimas, os eventos e as performances presentes nas rodas como artefatos discursivos, os quais nos fazem acreditar que na construção de autoria os/as jovens manifestam relevante agência na esfera cultural (urbana e digital), que é ao mesmo tempo pedagógica e política. Ao vislumbrarmos aspectos da construção de autoria, observamos os mecanismos de apropriação e criação de posições de sujeito que operam na produção e circulação de subjetivações, evidenciando como os/as jovens metaforizam e ironizam, a fim de denunciar e refletir sobre as violências e opressões diretas sobre a vida e os corpos, bem como sobre as objetivações normalizandoras e inferiorizantes que atuam nas formas de pensar, relacionar-se, e construir suas identidades.

Palavras-chave: Autoria. Subjetivação. Juventudes. Hip hop.

\footnotetext{
1 Bacharelada em Comunicação Social, Universidad Nacional de Córdoba, Argentina. Mestre e doutoranda em Educação em Ciências e Saúde (PPGECS) - Instituto NUTES Universidade Federal de Rio de Janeiro (UFRJ), Brasil. Orcid iD: https://orcid.org/0000-00021559-8354 E-mail: cw.valentina@gmail.com

2 Doutora em Educação em Ciências e Saúde (PPGECS) - Instituto NUTES - Universidade Federal de Rio de Janeiro (UFRJ). Professora colaboradora do Programa de Pós-Graduação em Educação em Ciências e Saúde (PPGECS) - NUTES - UFRJ/ Professora Permanente do Programa de Pós-graduação em Ciências Aeroespaciais (PPGCA) - UNIFA. Rio de Janeiro, Brasil. Orcid iD: https://orcid.org/0000-0003-4130-1646 E-mail: acostadasilva@gmail.com

3 Doutora em Educação, Columbia University. Professora Permanente do Programa de PósGraduação em Educação em Ciências e Saúde (PPGECS) - NUTES - UFRJ. Orcid iD: https://orcid.org/0000-0002-3574-8671. E-mail: verahfs@yahoo.com.br
} 
AUTHORSHIPS AND SUBJECTIVATION PATHWAYS: between rodas, rims and clips

\begin{abstract}
In this article, we analyze the construction of authorship and processes of subjectivation by a collective of hip hop that organizes "rodas culturais", in the complex of favelas of Manguinhos, Rio de Janeiro. Rodas culturais are initiatives of a public character, linked to the hip hop movement and of recent emergence in the carioca scene. With this scenario, we seek to understand such events and texts, in their live mode, as well as in the digital medias. We have assumed the rodas as cultural instances generating processes of subjectivation and subject positions, in its political, pedagogical, identity and symbolic dimensions. Based on the cultural studies in its poststructuralist dimension, we have taken the rhymes, events and performances present in the rhythms of the roda as discursive artifacts, which make us believe that in the construction of authorship the youth manifest relevant agency in the cultural sphere (urban and digital), which is both educational and politic. When we glimpse aspects of the construction of authorship, we observe the mechanisms of appropriation and creation of subject positions that operate in the production and circulation of subjectivities, evidencing how young people metaphorize and ironize in order to denounce and reflect on the direct violence and oppression of life and bodies, as well as the normalizing and inferiorizing objectivations that act in the ways of thinking, relating to others and constructing their identities.
\end{abstract}

Keywords: Authorship. Subjectivation. Youth. Hip hop.

\title{
PERCURSOS DE AUTORIA Y SUBJETIVACION: entre rodas, rimas y videoclips
}

\section{RESUMEN}

En este artículo analizamos la construcción de autoría y procesos de subjetivación por un colectivo de hip hop que organiza rodas culturais, en el complejo de favelas de Manguinhos, Río de Janeiro. Las rodas culturais son iniciativas de carácter público, ligadas al movimiento hip hop de reciente surgimiento en la escena carioca. Como problematización buscamos entender tales eventos y textos, en su modalidad en vivo, así como en los medios digitales. Por medio de un abordaje de investigación cualitativa, entendemos a las rodas como instancias culturales generadoras de procesos de subjetivación y posiciones de sujeto, en sus dimensiones: política, pedagógica, identitaria y simbólica. Con base en los estudios culturales en su vertiente postestructuralista, asumimos las rimas, los eventos y las actuaciones presentes en las rodas como artefactos discursivos que en la construcción de autoría los/las jóvenes manifiestan relevante agencia en la esfera cultural (urbana y digital), que es a la vez pedagógica y política. Sobre la construcción de autoría, observamos mecanismos de apropiación y creación de posiciones de sujeto que operan en la producción y circulación de subjetivaciones, evidenciando cómo los jóvenes, metaforizan e ironizan a fin de denunciar y reflexionar sobre las violencias y opresiones directas sobre su vida y sus cuerpos, así como sobre las objetivaciones normalizandoras e inferiorizantes que actúan en las formas de pensar, relacionarse y construir sus identidades.

Palabras clave: Autoría. Subjetivación. Juventudes. Hip-hop. 


\section{INTRODUÇÃO}

No acompanhamento das rodas culturais nasceu o contexto de pesquisa do qual tratamos neste artigo, em que, rimas, rodas, clipes e autorias, revelam as subjetividades de jovens que participam das atividades culturais na comunidade de Manguinhos, Rio de Janeiro ${ }^{4}$. As rodas, como atividades culturais, são eventos públicos, surgidos recentemente na cena carioca e ligados ao movimento hip hop. A modalidade de roda cultural, invariavelmente, se caracteriza pela ocupação de locais públicos com a participação de diferentes artistas, principalmente aqueles relacionados ao hip hop (rap, break, grafitti, batalhas de rima, freestyle, discotecagem, skate, poesia). Acompanhamos as rodas do coletivo Pac'stão 5 que se define nas suas mídias digitais como:

[...] um coletivo formado por jovens de diversas favelas que ocupam um espaço praticamente abandonado pelos nossos órgãos governamentais, temos uma Casa da Mulher FECHADA, Biblioteca FECHADA, Escola EM PÉSSIMAS condições, fora os constantes conflitos e tiroteios que passamos diariamente aonde moramos. Levamos oportunidades à CRIANÇAS E JOVENS que não têm condições de ir ao cinema ou assistir uma peça de teatro, [...] Hip hop é PAZ, AMOR, DIVERSÃO E UNIÃO para que a voz dos oprimidos seja escutada. Seguimos na luta and 6

É importante situar as rodas culturais e o hip hop em Manguinhos no contexto de experiências levadas a cabo por um tipo de juventude que está desenvolvendo, de forma ativa e organizada, práticas e discursos

\footnotetext{
${ }_{4}$ Manguinhos faz parte do complexo de favelas da cidade de Rio de Janeiro. Segundo o último Censo Nacional (IBGE, 2010), o bairro de Manguinhos alberga 15 favelas, 13.143 famílias, 44.051 habitantes. Especificamente em Manguinhos, teve importante impacto paradoxal a implementação do Programa de Aceleração do Crescimento (PAC), conjunto de políticas públicas de alcance federal para "estimular o crescimento econômico", criar "infraestrutura" e realizar "melhorias urbanas e de saneamento" em diferentes locais do Brasil. A implementação do PAC nesse complexo de favelas foi controverso produzindo além das "melhoras" graves repercussões negativas para parte de sua população.

5 As Rodas Culturais organizadas pelo coletivo do "Pac'Stão" aconteceram na praça do complexo PAC, localizada em frente à Biblioteca Parque (BPM) no Complexo de favelas de Manguinhos, Rio de Janeiro, todas segundas-feiras.

6 Extraído do comentário em Facebook publicado o dia 14 fevereiro 2017 no evento Manifesto Contra Proibição das Rodas Culturais do RJ. Disponível em:

https://m.facebook.com/story.php?story_fbid=1661736357459917\&id=1457694001197488.

Acesso: 6 jun 2017
}

Revista Exitus, Santarém/PA, Vol. 9, № 4, p. 695 - 719, Out/Dez 2019. 
diferenciados, que estimulam a sociabilidade, a manifestação pública e o exercício crítico, por meio de mediações ligadas ao movimento das artes e expressividades urbanas. Esses encontros, organizados e frequentes, se apresentam como experiências que favorecem criações e intercâmbios intersubjetivos, problematizando as questões identitárias e sociais que perpassam a construção de subjetividades dos sujeitos participantes. Nessa sintonia, como indica Holanda (2014) o hip hop, conforme a hibridação socio-identitária que adquire no Brasil, vem construindo um movimento interessante em termos culturais e políticos:

[...] O que une e define o hip hop no Brasil é a criação de um conjunto de ações mediadas pela cultura buscando a transformação de suas comunidades. Esta atitude (como é chamada), é agora experimentada simultaneamente como arte e ativismo. [...] capaz de articular um fórum supranacional de jovens pobres e pretos que levantam a bandeira da resistência (HOLANDA, 2014, p. 3).

Consideramos que abordar as manifestações desse movimento, num contexto específico como Manguinhos-RJ, pode contribuir na problematização/entendimento das tensões e potencialidades envolvidas nas juventudes de favelas e nos processos culturais, políticos e educativos por elas desenvolvidos.

A partir desse cenário de pesquisa entendemos o cultural conforme os estudos culturais na sua vertente pós-estruturalista. Para esse campo de estudos, uma cultura pode definir-se como o universo conceitual e as linguagens comuns que se compartilham para se referir ao mundo. (HALL, 1997). Assim, segundo Hall (1997), uma definição sucinta de cultura poderia se resumir no conjunto de coisas (que contém sentidos) e de processos e práticas que são produzidas e compartilhadas num determinado grupo ou sociedade. Quando se fala de sentidos, não só se coloca a dimensão cognitiva (significados), mas também as instâncias emocional e ideológica, todas estas constitutivas das identidades sociais. Desta forma, os sentidos transcendem seu caráter simbólico, influenciando as atitudes e condutas, produzindo práticas de organização e regulação das interações 
interpessoais. Nas palavras do autor, os sentidos compartilhados não só "estão na cabeça"; de fato, têm efeitos práticos reais: "Damos sentido às coisas conforme as usamos, conforme as integramos em nossas práticas cotidianas" (HALL, 1997, p.3, tradução nossa). Cultura envolve, assim, o conjunto de práticas que carregam sentidos e valores que, ao serem interpretados por "outros", operam efetivamente como sistema de representação. Nessa perspectiva, a cultura coloca-se como o domínio simbólico inerente a toda sociedade, a todo grupo humano que interage coletivamente. Com base nessa perspectiva, compreendemos então as práticas culturais das juventudes como experiências de vida integrais, nas quais narrativas e ações se entrelaçam na construção de subjetividades, construção que necessariamente supõe a presença do outro, de uma alteridade, ou seja, o estabelecimento de vínculos mediados por relações de afetividade, sociabilidade e poder.

Na perspectiva da pedagogia crítica, Giroux (1999) elabora um conceito de pedagogia intimamente relacionado à cultura e à política. Para o autor, as práticas pedagógicas são formas de fazer política com a cultura, dado o fato de estarem sempre implicadas "na construção e organização de conhecimento, desejos, valores e práticas que transpassa diferentes linguagens, atividades e espaços sociais" (p. 14). Assim, assumimos teoricamente que os/as jovens no desenvolvimento das suas práticas culturais, realizam uma dupla agência, que é ao mesmo tempo pedagógica e política. Dessa forma, neste artigo, buscamos analisar a construção de autoria e processos de subjetivação por um coletivo de hip hop que organiza rodas culturais, num complexo de favelas da cidade de Rio de Janeiro. Aprofundamos a dimensão dos processos de subjetivação que ocorrem nos contextos culturais e discursivos, articulando tal discussão com a perspectiva foucaultiana que problematiza os processos de construção de autoria.

Foucault concebe a escrita (e demais produções) sempre em um processo de ser refeita, transgredida, retificada. Em outras palavras, a escrita (o discurso) seria um espaço onde o autor está sempre em vias de 
desaparecer. Ainda na perspectiva foucaultiana, entendemos os "modos de subjetivação" como as práticas de constituição do sujeito, as quais se dão não só a partir de imposições que the são exteriores - produto das relações de saber e de poder - mas também, a partir de relações intersubjetivas em que há espaço para, em uma relação de si consigo, se pensarem de outra forma, como sujeitos que oferecem resistência às técnicas de dominação, ou seja, que encontram brechas para exercer a liberdade.

Apresentamos a seguir uma breve discussão sobre juventudes, a fim de caracterizar como a categoria teórica vem sendo discutida, aprofundando a discussão sobre os discursos relativos "aos problemas" associados a este recorte etário. Com o entendimento dos/das jovens como sujeitos sociais heterogêneos e ativos, indagamos sobre as possibilidades de sua agência cultural e pedagógica, inseridos no movimento cultural hip hop presente também na atual "era digital".

Em seguida, após breve caracterização do hip hop e dialogando com o referencial teórico metodológico assumido, ampliamos o olhar sobre o conceito de autoria, situando a "função-autor" como um desdobramento da função do discurso, uma vez que "[...] a função-autor é característica do modo de existência, de circulação e de funcionamento de certos discursos no interior de uma sociedade" (FOUCAULT, 2015, p.174, grifo nosso). Ou seja, na contramão da profusão de textos da era digital, a unidade e coerência de uma obra surgem como resultado de processos complexos relacionados à identidade de um (ou mais) sujeito(s) construído(s). Esta relação dual, entre discursos "in/excluídos" e construídos "sobre/por" jovens em Manguinhos que nos leva à percepção de que as rimas, os eventos e as performances presentes nas rodas são artefatos discursivos e de que, a construção de autoria destes jovens, os fazem sujeitos que manifestam, para além de condições juvenis precarizadas (REGUILLO, 2013), relevante agência na esfera cultural, com seus respectivos desdobramentos pedagógicos e políticos. 


\section{OS/AS JOVENS CONTEMPORÂNEOS/AS E SUA INSERÇÃO NA CULTURA E NAS MÍDIAS DIGITAIS}

No Brasil, o Estatuto da Juventude estabelece como jovem "as pessoas com idade entre 15 (quinze) e 29 (vinte e nove) anos de idade" (BRASIL, 2014, art. 1). Já na classificação educativa, os jovens são catalogados segundo sua inserção como "alunos/estudantes", conforme diferentes períodos de escolarização (últimos anos do ensino fundamental, ensino médio, educação superior/universitária/técnica). Se indagarmos sobre os sentidos outorgados ao termo, os romanos relacionavam a juventude com uma etapa produtiva, madura da vida7, enquanto, na modernidade tardia, vincula-se com uma fase anterior, de "percurso preparativo", de "desenvolvimento para atingir a maturidade".

Nos estudos contemporâneos sobre juventudes, as definições sobre a "questão juvenil" se apresentam historicamente situadas. Em conformidade com essa corrente, Abramo (2008) define a condição juvenil como aquele modo em que:

[...] uma sociedade constitui e atribui significado a esse momento do ciclo de vida, refere-se a uma dimensão histórico-geracional, ao passo que a situação dos jovens revela o modo como tal condição é vivida a partir dos diversos recortes referidos às diferenças sociais classe, gênero, etnia etc. (ABRAMO, 2008 apud BRASIL, 2014, p. 13).

Segundo Dayrell (2003), fazendo referência a Charlot (2000), a condição de jovem como sujeito social supõe compreendê-lo como ser humano aberto a um mundo historicamente construído, que é portador de desejos e motivações e que vivencia sua trajetória nesse mundo a partir de relações com outros. A partir dessa definição de sujeito, identificamos três componentes constitutivos em permanente relação. Por um lado, o caráter de sujeição, ou seja, de condicionamento, dado pela situacionalidade histórica e social onde o sujeito nasce e se constitui. Por outro, o reconhecimento de uma subjetividade intrínseca e singular, que dá espaço

\footnotetext{
7 "Jovem" provém do latim iuvenis, do verbo iuvare que significa "ajudar e sustentar, ser o apoio produtivo da sociedade". Extraído de: <http://etimologias.dechile.net/?joven>. Acesso: 17 jun 2017, tradução nossa.
} 
para pensar o ser humano em sua potencial liberdade de ação, de manifestação de desejo, de "indeterminação" e criação sobre esse mundo condicionante. Finalmente, um componente de alteridade, pois não existe sujeito se ele não mantém relações materiais e simbólicas com os outros sujeitos.

Zluan e Raitz (2014), na sua reconstrução histórica dos estudos sobre juventudes no Brasil, indicam que é nos anos 1990 que o "jovem" começa a ser estudado como "protagonista da sua própria história", sendo anteriormente reconhecido só como agente associado a "problemas" e "desvios":

Por longas décadas, os jovens foram analisados por olhares adultocêntricos que, a partir das convicções particulares do mundo adulto e de certas definições cronológicas, definiam as características reconhecidas como 'normais', e todos aqueles que se desviassem desses padrões eram considerados como problemas (ZLUHAN; RAITZ, 2014, p. 259-60).

Assim, as pesquisas tradicionais com base no "olhar adultocêntrico", têm reafirmado o caráter transitório do "ser jovem", no sentido de ser contemplado como um sujeito que "virá a ser", sem reconhecer as prioridades, projetos, vivências e agências dessa etapa de vida (ZLUHAN e RAITZ, 2014).

Essa compreensão do jovem como "agente social" complementou a visão legalista do jovem como sujeito de direitos e introduziu uma caracterização de "maior autonomia" comparada às crianças e aos adolescentes púberes, como também, diferenciada da esfera dos "adultos". Segundo Groppo (2016), os intelectuais que principalmente impulsionaram essa perspectiva foram de origem europeia e ibero-americana.

No paradigma de sujeito social, surgem assim, nos dispositivos de saber/poder oficial, novas categorias que são imediatamente associadas aos jovens. Dessa forma, o jovem é objetivado a partir de práticas e condutas de "protagonismo social": "O jovem" como ator estratégico de desenvolvimento, como empreendedor, com competências úteis, como voluntário, participativo, empoderado etc. (BORGOSHIAM, MINAYO, 2009; CARRANO, 2013, GROPPO, 2016). 
Os jovens interagem e se socializam em vários espaços e na atualidade encontram-se inseridos em um mundo imerso pela cultura digital. Como indicam os resultados das pesquisas incluídas em "Jóvenes, culturas urbanas y redes digitales" (CANCLINI, CRUCES, POZO, 2012), o modo de ser jovem hoje, pressupõe o trânsito entre o mundo on-line e o off-line. No entanto, deve-se relativizar a ideia de inserção plena e "igualitária" em termos de acesso a equipamentos e infraestruturas digitais, dado que conforme indica Reguillo (2013), as juventudes contemporâneas se desenvolvem em circuitos socioculturais diferenciados, sendo relevante atentar para dispositivos e condições que habilitam processos de inclusão desigual.

\section{O HIP HOP CARIOCA COMO CIRCUITO URBANO-CULTURAL JUVENIL}

Dentro dos circuitos culturais juvenis, focamos na caracterização do hip hop por ser este o tipo de cultura/arte urbana em torno da qual as rodas culturais se dinamizam. Como recupera Fonseca (2011), o termo hip hop deriva dos termos ingleses hip (quadril) e to hop (saltar, pular). Com origens na capital jamaicana de West Kingston, o hip hop surgiu nos bairros marginais da cidade de New York nos Estados Unidos na década de 1970 onde juventudes migrantes negras e latinas moravam. Como estilo musical/poético, combina a performance do MC (Mestre de Cerimônia) que desenvolve a fala e a do DJ (Disc-Jockey, DeeJay) que a partir do manuseio de duas bandejas de discos, mixagens e outros efeitos sonoros (back to back, scratch, quick cutting) produz a música (FELIX, 2005). Pesquisas sobre hip hop mencionam o seu caráter integral como cultura/movimento, pois desde seu início, além de uma estética e modo de vida particular, apresenta elementos de crítica social e protagonismo público a partir da geração de espaços relativamente autônomos (OLIVEIRA, 2015; FONSECA, 2011, D'ANDREIA, 2013, RIBEIRO, 2016).

Com o processo de globalização, o hip hop chega ao Brasil em meados dos anos 1980, como prática cultural de lazer subalterna. Como indica Oliveira (2015), a reconfiguração do hip hop no Brasil trouxe um 
deslocamento particular numa prática que já, nas suas origens, se apresentava contra oficial e híbrida. De fato, em várias cidades brasileiras, com o intuito de se diferenciar de outros estilos dentro da cultura do popular, um tipo específico de hip hop engajado começa a ganhar espaço na cena under urbana. Raps de contestação e denúncia, que "[...] ao transitarem por crimes, mortes, violência, drogas, conflitos sociais e miserabilidades de todos os tipos" interpelavam diretamente aos setores sociais hegemônicos, que, ora desacreditavam do valor estético da música, ora denunciavam sua apologia à anomia e à desestruturação social (OLIVEIRA, 2015, p. 69).

Hoje em dia é difícil conseguir dar conta do complexo circuito cultural da cultura/movimento hip hop e da quantidade de manifestações a ele associadas. Rodas de rima, campeonatos de batalhas, slams, shows, produtoras, etc., circulam, se relacionam, produzem, são consumidos em diferentes níveis (nacional, estadual, regional, local). Neste sentido, podemos dizer que o movimento hip hop no Brasil apresenta-se como uma prática rizomática e dinâmica, ligada a grupos sociais subalternos, que expressam uma identificação multifacetada a partir do reconhecimento e da defesa de uma situação social (morar na favela, na periferia), de classe (popular/trabalhadora/oprimida) e de raça (negra).

O hip hop permeia diferentes práticas e manifestações artísticas no circuito de lazer dos jovens de Manguinhos, RJ: A Roda Cultural de Pac'Stão, encontros de poesia, apresentações de MCs e DJs locais, slams, entre outras. Muitos/as jovens participam de diferentes espaços e atividades relacionadas à cultura hip hop, representando essa identidade. Curtem artistas de rap (nacionais e locais); se identificam com o conteúdo das letras e com a dinâmica de produção da prática; produzem conteúdo a partir de fotos e vídeos que compartilham nas redes sociais e na plataforma YouTube.

As produções dos artistas locais (vídeo clipes de coletivos e artistas de hip hop, vídeos de poetas, fotografias de grafites, promoção e registro de eventos etc.) podem ser encontradas na Internet, principalmente nas plataformas de mídias sociais digitais (MSD). Nesse sentido, como indica Amaral (2017), reconhecemos a indissociabilidade entre os mundos on e off- 
line nas práticas culturais abordadas, dada a continuidade entre o momento de produção "ao vivo" e a distribuição e consumo nas mídias digitais.

\section{SOBRE AUTORIA E SUBJETIVAÇÃO}

Como analisaremos neste artigo, tanto as rimas como o caráter performático e a escolha pelos cenários "reais" nos videoclipes, são aspectos que permitem entender essas produções como discursos autorais de subjetivação dos próprios jovens. Nas palavras de Larrosa (1994) o processo de subjetivação refere à prática de "se-narrar", de se apresentar ao mundo a partir da sua própria realidade, seus próprios corpos e lugares, suas próprias experiências conforme as diferentes posições que o produtor do discurso assume.

A fim de avançar na análise, propomos algumas questões sobre estes sujeitos produtores de discursos e práticas no circuito hip hop carioca: quais seriam os modos de existência desses discursos? Quem poderia preencher as diversas funções de sujeito? Quais subjetivações se evidenciam? E afinal: por que importa quem fala?

Com tais indagações voltamos o olhar sobre a relação do autor e sua obra, na construção da autoria e em como estes jovens se constituem como autores de discursos que circulam, que são repetidos, cantados, visualizados no Youtube e reconhecidos por outros/as jovens.

Sobre a autoria, na perspectiva foucaultiana, podemos evidenciar quatro características assim resumidas:

[...] a função autor está ligada ao sistema jurídico e institucional que contém, determina, articula o universo dos discursos; ela não se exerce uniformemente e da mesma maneira sobre todos os discursos, em todas as épocas e em todas as formas de civilização; ela não é definida pela atribuição espontânea de um discurso ao seu produtor, mas por uma série de operações específicas e complexas; ela não remete pura e simplesmente a um indivíduo real, ela pode dar lugar simultaneamente a vários egos[...] (FOUCAULT, 2015, p. 283-284, grifo nosso).

Assim a "função autor" conceituada por Foucault (2015), demonstra que o autor é "[...] apenas uma das especificações possíveis da função 
sujeito" (FOUCAULT, 2015, p. 291). Deste modo, pode-se perceber o lugar da liberdade e da expressão do sujeito, e com isso observar as condições pelas quais se tornou possível um processo que permite ao(s) sujeito(s), aparecer como proprietário e responsável pelo discurso. Ou seja, este "nome" de autoria carrega uma injunção simbólica sobre outros dizeres: "[...] garantindo-lhe (ou não) sua força de verdade, seu eco e sua permanência (sempre relativa) na história" (CURCINO, 2014, p. 82).

Na concepção foucaultiana, o nome do autor não está ligado ao indivíduo real, mas nos leva a um certo tipo de discurso, com perfil característico. Com isso, é preciso observar as modalidades de existência de cada autoria, pensando o regulamento discursivo que se estabelece, sempre ressaltando que o nome do autor funciona como forma discursiva de classificação e delimitação de um conjunto de textos, e de uma maneira específica de enunciação. Nesta perspectiva: "o nome do autor não está localizado no estado civil dos homens, não está localizado na ficção da obra, mas na ruptura que instaura um certo grupo de discursos e seu modo singular de ser" (FOUCAULT, 2015, p.278).

Com este aporte teórico, podemos estudar os discursos não somente por suas transformações formais ou sua expressividade, mas nas suas modalidades de existência: os modos de circulação, de valorização, de atribuição, de apropriação, em suas variáveis, de acordo com cada contexto cultural. Será a partir deste olhar que poderemos "[...] apreender os pontos de inserção, os modos de funcionamento e as dependências do sujeito" (FOUCAULT, 2015, p. 291). A autoria surge, assim, como umas das especificações possíveis da função sujeito, de modo a analisá-lo como uma função variável e complexa do discurso, interrogando seu papel de fundamento originário.

Para Castro (2009) Foucault é levado a uma história das práticas de construção do sujeito, sendo os "modos de subjetivação" precisamente as práticas de constituição do sujeito. Entre as definições descritas para o termo "subjetivação", interessa-nos a que explicita os modos de subjetivação como modos de objetivação do sujeito, "[...] isto é, modos em que o sujeito 
aparece como objeto de uma determinada relação de conhecimento e poder" (CASTRO, 2009, p.408). Assim, as subjetivações evidenciadas pelas posições de sujeito revelam as condições em que se formaram e modificaram as relações entre o sujeito e o objeto, para tornar possível uma forma de saber. Neste caso, formas de saber autorais, no universo do hip hop carioca.

\section{DA RODA AO VÍDEOCLIPE}

Na pesquisa desenvolvida8, a observação etnográfica-participante foi realizada durante dez rodas culturais que aconteceram na Praça do PAC em Manguinhos-RJ, entre setembro de 2016 e junho de 2017. Como pesquisadora, a primeira autora cumpriu o papel de "assistente das rodas", compartilhando o espaço e interagindo com os/as jovens que assistiram a esses encontros. O trabalho de observação etnográfica-participante foi acompanhado por uma abordagem das mídias digitais, principalmente daquelas criadas pelo coletivo que organiza a roda como também outras, de outros agentes relacionados ou aficionados. Estas mídias favoreceram a visibilidade e compartilhamento dos eventos e produtos discursivos produzidos por artistas vinculados às rodas. A opção por "ir para as plataformas digitais" se justificou pela continuidade entre os eventos "ao vivo" e a dinâmica digital, articulando-se ambas dessas instâncias de produção/circulação/consumo cultural (ROGERS, 2009, AMARAL, 2017, SCOLARI, 2016a).

No trabalho de campo, constatamos como as rodas em Manguinhos, $\mathrm{RJ}$, se preocupam com o desenvolvimento de um processo que tem como horizonte "[...] mobilizar conhecimentos e desejos que possam conduzir à minimização do grau de opressão na vida das pessoas" (GIROUX, 1999, p. 15). Isso ficou evidente no discurso público da roda do Pac'Stão, tanto nas mídias digitais como nos eventos ao vivo. Conforme Giroux (1999), consideramos então as rodas como um tipo de prática social que expressa

\footnotetext{
8 Dissertação de Mestrado defendida no NUTES/UFRJ em 2017.
} 
um modo particular de política pedagógico-cultural, sendo espaços juvenis de discursividade.

Segundo Foucault (2008) todo discurso significa o ato de "fazer coisas com palavras", pois daquilo "que se fala", "como se fala", "quem fala", "para quem se fala" e "para que se fala" adquire uma unidade específica orientada a um fim que é possível de ser observado na sua superfície, ou seja, na materialização de diferentes performances verbais ou de outra índole simbólica.

Especificamente neste trabalho, abordamos a partir de uma análise discursiva uma das produções que consideramos significativa para nossas indagações. Trata-se do clipe, difundido no YouTube, "Straight Outta Pacstão!" (SOP)9, cypher produzido pelo Coletivo Pac'stão e lançado nas redes em março de 2017. O vídeo atualmente conta com mais de 45 mil visualizações e mais de 2.800 curtidas. Foi realizado a partir da parceria de artistas da cena hip hop de Manguinhos, RJ (MCs, B-boys) e a produtora independente Grito Filmes ${ }^{10}$, iniciativa que gera conteúdo audiovisual sobre rodas de rima e outros eventos de hip hop no contexto da cidade e de regiões próximas.

\section{ELEMENTOS DISCURSIVOS DO CLIPE COMO MARCAS DE AUTORIA}

Antes de apresentar a análise da letra, consideramos importante focar alguns aspectos relativos às condições de produção e elementos visuais do material, entendidos como constituintes da construção de autoria.

Primeiramente, é importante esclarecer que se trata de um cypher, ou seja, uma proposta colaborativa que reúne cinco MCs num momento criativo $^{11}$. No início do movimento hip hop os MCs faziam referência a encontros de improvisação baseados no freestyle. Conforme informações

\footnotetext{
9 Título/Link: [Cypher] Straight Outta Pacstão! Coletivo Pac'stão + GritoFilmes. Data de Publicação: 29 mar 2017. Ficha técnica: Direção, Filmagem e Edição: Ian Miranda. Produção: Chrisbeatszn. Voz: 2D, Xandy, Leonicio, Tapre, Maya. Dançarinos: Isaque IDD e Severo IDD / Thoney \& Dopre. Licença Youtube: Padrão. Acesso 10 jul 2018,

10 Página de Facebook do Grito Filmes: https://www.facebook.com/gritofilmes/

11 Fonte sobre o termo cypher: Rap.Wiki http://es.rap.wikia.com/wiki/Cypher . Acesso 20 jul 2017.
} 
fornecidas por um artista hip hop de Manguinhos, o cypher simboliza o círculo perfeito (as áreas da vida onde se tem total controle), o número zero, na cosmologia dos percentistas (Five-Percent - Nation of Gods and Earth), corrente político-religiosa ligada ao Islã, nas origens do hip hop e do movimento negro nos Estados Unidos. ${ }^{12}$

Atualmente, nas redes digitais, encontramos muitos videoclipes baseados nessa modalidade de cypher. No SOP o cypher, além de ter MCs homens (o mais comum no universo do rap), também incorpora B-boys (dançarinos), uma MC mulher e uma cantora de soul, black music e samba; todo/as eles/elas artistas jovens de Manguinhos.

Em segundo lugar, reconhecemos alguns primeiros aspectos discursivos significativos. O clipe é filmado num antigo prédio militar atualmente abandonado, considerado espaço "tabu" da favela. Apesar dessa representação, durante nosso trabalho de campo percebemos certa apropriação do prédio por parte dos jovens, a fim de produzir um espaçocenário de lazer e criação cultural.

Esse aspecto simbólico-territorial, de mostrar nos vídeos os ambientes da vida cotidiana dos artistas, é um constante recurso cenográfico da arte urbana ligada ao hip hop. Os elementos imagéticos dos vídeos percorrem as ruas, becos, lugares urbanos, apresentando os caminhos, as paisagens, os ícones socio-territoriais dos/as jovens. Dessa forma, podemos dizer que nos vídeos existe um interesse por articular as rimas com o "ambiente" onde elas foram produzidas, enfim, evidenciando as condições de vida que permitiram essas batidas e essas falas. Entendemos isso como um tipo de "testemunha ambiental" que funciona como um reforço ao efeito discursivo das letras.

Outro aspecto interessante é o caráter performático do videoclipe (FIRTH, 1988). O artista se apresenta "tal qual é", no ambiente "natural" onde geralmente faz sua arte, desenvolve parte importante de sua sociabilidade, onde vive sua vida. Dessa forma, o foco audiovisual está centrado no artista, nos seus gestos, seus movimentos, sua expressividade. Como indica

12 Para maiores informações consultar a matéria do seguinte link: https://dnaurbano.com.br/publicacoes/cypher Acesso. 5 nov 2017. 
Mozdzenski (2013), esse tipo de videoclipe se apresenta propício para o reconhecimento dos aspectos identitários e das capacidades técnicas dos artistas, sendo a pretensão de autenticidade uma das estratégias discursivas. O importante é que o público que assiste acredite (e se identifique) no/com o vídeo, que o que vê e ouve tenha um efeito de "realidade", principalmente em relação ao virtuosismo artístico e às características subjetivas de quem executa a prática. No clipe analisado -como na maioria das produções de hip hop - o caráter performático é evidente.

Sobre este aspecto, no clipe abordado, os/as MCs e os B-boys, são os elementos imagéticos centrais. Os planos se adaptam para capturar sua expressividade facial e seus movimentos, pois não se trata só da rima, senão também de como o corpo transmite o ritmo, a estética e a "transgressão disciplinar" contida no hip hop.

Sobre a estética, cabe esclarecer que no SOP não aparecem, no figurino, elementos de "luxo", tão presentes nos vídeos comerciais de rap (tênis caros, relógios e correntes de ouro). Os artistas estão vestidos como normalmente costumam fazê-lo: à moda hip hop das camadas jovens das favelas. No lugar de carros caríssimos, as bicicletas; no lugar de um monte de mulheres provocativas, as "minas" rimando junto aos "manos". Isso condiz com o que temos observado nos posicionamentos públicos do coletivo Pac'Stão: o interesse não está em reproduzir um hip hop comercial, banal, sexista, consumista, senão em promover outros valores ligados à identidade de favela, à reafirmação da cultura negra e urbana, às vantagens do trabalho em equipe e à necessidade de lutar por se manter vivos e levar em frente projetos diferentes aos "predestinados".

\section{PERCURSOS DE AUTORIA NO CONTEÚDO DISCURSIVO DAS RIMAS}

Começamos a análise da letra da música pelo título, entendido como um enunciado, no qual identificamos dois elementos discursivos. Em primeiro lugar, a escolha das palavras "Straight outta" e a seguir, a referência ao nome do coletivo "Pac'Stão". Sobre o nome do coletivo, "Pac'Stão" o termo representa três elementos articulados: uma referência topográfica (ao PAC, 
como espaço público emblemático no atual Manguinhos, RJ), uma referência bélico-conflitiva (ao país Paquistão em que a situação de guerra se assemelha à vivida pelos jovens da favela) e uma identificação afetiva para o "fazer cultural" (na sigla PAC, ressignificada "Por Amor à Cultura").

Já "Straight outta" indica outra intertextualidade. Em 1988, umas das primeiras bandas de hip hop da cidade de Los Angeles (LA), Niggz Wit Atitude ("Negros com atitude", conhecida por sua sigla N.W.A) lançou a música e o disco homônimo Straight Outta Compton ("somos de Compton"). Nos anos 1980, Compton era uma das cidades mais pobres e inseguras nos arredores de LA. O local encontrava-se dominado pela guerra entre gangues que disputavam o controle sobre o território para a venda de cocaína e crack $^{13}$. A intertextualidade proposta no clipe analisado remete então, a esse elo entre N.W.A., Compton, LA, USA, 1988 e o Pac'Stão, Manguinhos, RJ, Brasil, 2017.

Figura 13. Flyer do filme lançado em 2015 sobre a história da banda N.W.A

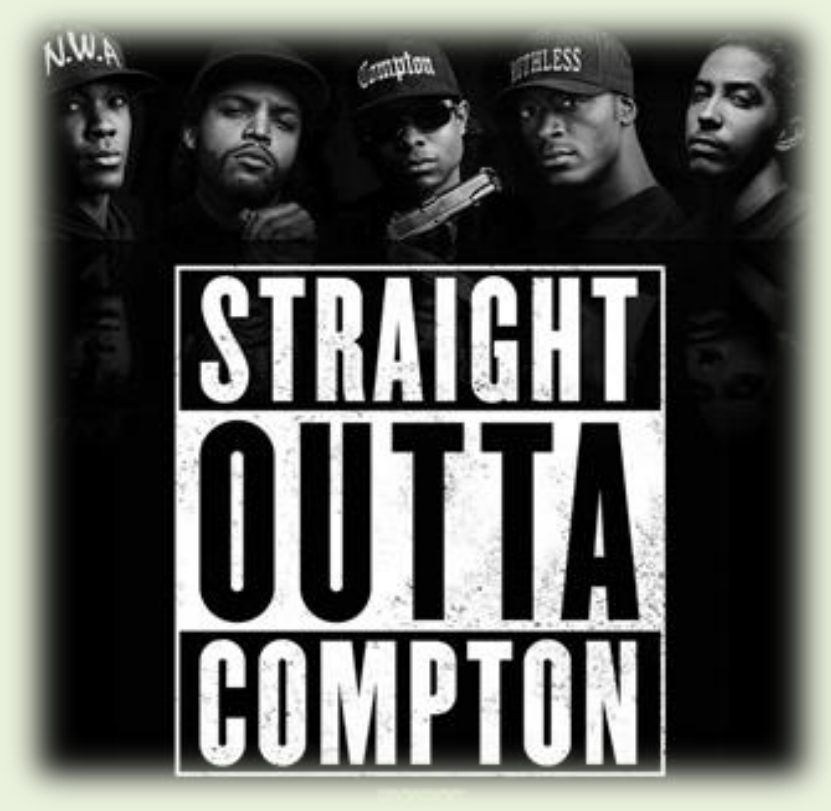

Fonte: google imagens. link $^{14}$

13 Atualmente Compton é um subúrbio de LA. Continua no topo dos índices de pobreza e criminalidade dos Estados Unidos.

14https://images.rapgenius.com/9e9dacad2241c98c0d021cc8e373claa.1000x1000x1.jpg Acesso: 1 ago 2017.

Revista Exitus, Santarém/PA, Vol. 9, № 4, p. 695 - 719, Out/Dez 2019. 
Figura 14. Camisetas no marco da difusão do "Straight outta Pac'Stão"


Fonte: Página de Facebook, roda cultural do Pacstão ${ }^{15}$.

No caso do Brasil, nas origens do rap Nacional encontramos referências exemplares nas letras de Os Racionais MCs, Sabotage, MV Bill, Facção Central, entre tantos outros artistas, que criaram rimas e batidas para retratar "a vida real" e o "papo reto", exercendo o direito à denuncia e à crítica sobre diversas situações de opressão, preconceito e violência urbana.

\section{A AUTORIA ENTRE METÁFORAS, IRONIAS E DENÚNCIAS}

A seguir, retomamos alguns trechos da letra "Straight Outta Pac'Stão" que nos permitem realizar uma leitura sobre como os jovens estão se narrando nas letras da música por meio de diferentes estratégias discursivas. Entre estas estratégias reconhecemos: a) o uso autoral da metáfora para ressignificar a vida em contextos urbanos perpassados pela violência e a falta de oportunidades; b) o recurso da ironia para ressignificar estereótipos e; c) a poética da rima como denúncia dos processos racistas e de violência de Estado.

a) A autoria na metáfora natural para a ressignificação da vida urbana

\footnotetext{
15 Publicações do 22 de março e 15 abril 2017:

https://www.facebook.com/poramoracultura/photos/a.1469008826732672.1073741832.14576 94001197488/1677187862581433/?type=3\&theaterhttps://www.facebook.com/poramoracult ura/photos/a.1682957515337801.1073741858.1457694001197488//1682958335337719/? type=3\& theater Acesso 1 ago 2017.
} 
Tal como observamos nos seguintes trechos, um primeiro recurso literário que caracteriza a autoria das rimas relaciona-se com o uso de figuras da natureza para ressignificar estigmas sociais urbanos:

Já me iludi tentar ficar rico, até perceber que rico eu já tava Cheio de saúde, rico de amores

Colhendo sempre tudo o que eu plantava.

Se engana quem passa na selva urbana cheio de ideia profana,

falando que aqui só tem crackudo.

A vida é bela, mas tem seus perigos como uma rosa e seus espinhos

eu tenho fé e persisto

sou Zona Norte e favela eu respiro.

Neste movimento literário reconhecemos uma função-autor que procura trazer a vida, o crescimento, a colheita, a beleza da flor, àquelas situações que são próprias do mundo urbano. Com isto, a autoria na rima revive a cidade, e o sujeito discursivo coloca-se como criador: quem planta, colhe, transita pela selva, observa a beleza da rosa e o perigo dos espinhos.

b) O autor irônico contra o poder dos estigmas

Outra estratégia, também metaforizante e subjetivadora faz alusão ao uso de palavras associadas aos estigmas da criminalidade e da marginalidade para construir, a partir da ironia, o sujeito autoral da música. Como se observa na seguinte rima:

\author{
Nesse crime eu tô envolvido, \\ olha só quanto bandido \\ De mente livre, então se previne \\ Que de R.A.P somos todos nutridos
}

Neste trecho, o MC faz um jogo de palavras entre crime, bandido, mente livre e R.A.P. Assim, com base na metáfora irônica, a rima indica o discurso hegemônico da criminalização dos jovens que moram nas favelas, sendo que, o único "crime" reconhecido por eles, é que têm a "mente livre" por estarem "nutridos" do rap. Neste sentido, identifica-se um autor que resiste, por meio da ironia ressignificante, aos estereótipos que objetivam de forma unívoca e homogênea os jovens de favelas como "perigosos", 
aqueles indivíduos pobres e negros de quem a "sociedade" deve "prevenirse" e "proteger-se".

c) A rima como denúncia

A autoria na rima também se apresenta com uma função de denúncia. Como se observa a seguir, os alvos de denúncia são claramente identificáveis. Por um lado, confronta-se o Estado, aquele que não é reconhecido no seu sentido "público" pelo autor da rima:

\section{A segurança não é pública \\ Portanto tolo é quem acredita no encanto \\ Ela é que nem TV antiga, às vezes nem liga \\ Só enxerga o preto e branco.}

Na rima, na comparação estabelecida entre o Estado e uma "TV antiga" (que só funciona "em preto e branco") apresenta-se uma analogia tecnológica para "figurar" o racismo dos agentes de segurança estatal, garantidores, por meio do controle e da repressão, da necropolítica racial e classista, que mantém "a ordem" e os privilégios hegemônicos.

Esse racismo também envolve a "guerra contra as drogas" e suas devastadoras consequências para as juventudes das favelas. Sobre este aspecto, em outro trecho da música, observamos uma referência também instigante sobre como o mercado de drogas está "liberado" em outras áreas "nobres" e "turísticas" da cidade carioca:

Cheio de gringo com dólar, pra dentro joga a coca Combate contra as droga é bem mais raro em $\mathrm{Copa}^{16}$ (Xandy $\mathrm{MC}$ ).

Estas passagens de autor-denúncia dão conta de como, na construção das rimas, existe uma problematização e posicionamento sobre as estratégias de poder/opressão que operam sobre os jovens de favelas.

\footnotetext{
${ }^{16}$ Copacabana, bairro turístico da zona sul da cidade do Rio de Janeiro
} 


\section{AUTORIA, SUBJETIVAÇÃO E CONFLITO PELA PALAVRA}

Coerentemente com nossos objetivos, observamos como os papéis de autoria estão compartilhados entre os jovens que compõe o grupo. Notamos que as rimas se apresentam como eixo norteador ao oferecer visibilidade aos discursos que circulam sobre a juventude que mora ou frequenta as favelas, apontando outra perspectiva, para além dos estigmas sociais construídos sobre as juventudes pelos discursos de poder.

Os processos de subjetivação operam através das funções-autor como janelas para uma dimensão desconhecida de grande parcela da sociedade. Com isso, se os/as jovens das favelas e periferias são objetivados/as dentro de um espectro negativo na circularidade que os restringe a um único lugar, as diferentes posições de sujeito evidenciadas nas rimas se deslocam para linhas de fuga que ora evidenciam denúncias e injustiças, ora apontam outras facetas da realidade que compartilham e ressignificam a vida nas conturbadas megalópoles brasileiras.

Assim, se predominantemente um projeto de autoria trabalha para a unidade da obra ou da mensagem a ser dita, os autores da música analisada investem para além da marcação de distinções entre os discursos e, com isso, a configuração de autoria funciona gerenciando a proliferação da linguagem, dando aos enunciados um projeto e uma coerência ligados ao acordo implícito de um pensamento coletivo, em prol da denuncia à opressão. Desta maneira, corrobora-se o que assinala Reguillo (2018) sobre os processos de subjetivação que se produzem nos trânsitos socio-culturais juvenis. Das ruas às mídias digitais, para além da procura por reconhecimento e visibilidade, emergem com o intuito de "litigar a palavra", posicionando-se sobre sentidos e representações em relação a questões que perpassam a disputa público-política.

A respeito da autoria, é possível dizer que no caso das rimas analisadas, a identidade autoral é construída por vários ingredientes: performances, vídeos, vestuário e a unidade de um corpo de rimas que se materializa como fonte de expressão e discurso, buscando assim, existir 
como subjetividade e singularidade de ser jovem da favela, ser do PAC, ser de Manguinhos.

\section{CONSIDERAÇÕES FINAIS}

Ao longo deste trabalho, apresentamos as rodas culturais de Manguinhos - no marco do movimento das rodas culturais e do hip hop carioca - na sua dimensão cultural e juvenil e seus desdobramentos pedagógicos e políticos. Assim, com base nos estudos culturais em sua vertente pós-estruturalista, olhando para os sujeitos, os poderes e a cultura problematizamos as rodas como práticas e discursos na construção de autoria.

Ao vislumbrarmos aspectos da construção de autoria na música analisada, observamos os mecanismos de apropriação e criação de posições de sujeito que operam na produção e circulação de subjetivações, evidenciando como os/as jovens metaforizam e ironizam a fim de denunciar e refletir sobre as violências e opressões diretas sobre a vida, bem como sobre as objetivações normalizandoras e inferiorizantes que atuam nas formas de pensar, relacionar-se e construir suas identidades.

Neste sentido, na análise apresentada identificamos um discurso de caráter coletivo e identitário. Por meio das rimas, os jovens se apropriam da palavra, misturando, num estilo poético próprio diversas figuras retóricas para contar quem são eles, o que fazem e, como refletem sobre suas realidades. Assim, os processos autorais de rimas, clipes, e rodas se apresentam como instâncias de discurso que permitem o acesso a como eles/as se posicionam frente ao que significa ser jovem, negro/a, morador/a de favela, evidenciando várias formas de agência e posições de sujeito. Desta maneira, o discurso produzido no marco das rodas é subjetivador e subjetivante, dado que sinaliza a transformação de estigmas sociais em emblemas identitários (REGUILLO, 2000) não só para os artistas autores senão também, para o público aficionado. Desta forma, os corpos, as experiências, a arte e as modalidades de resistência das populações das favelas são 
produzidas e valorizadas no acontecer das rodas culturais e de seus contextos de produção digital.

Observamos também que a consciência dos mecanismos de poder/opressão está presente no movimento hip hop de Manguinhos. Construída através da autoria a legitimidade desse saber emergente e se sustenta no fato de "se falar" a partir das próprias experiências e situações de vida, as quais são também reconhecidas e reafirmadas pelo público que escuta, curte e compartilha o clima, as mensagens e, as batidas das rodas.

Neste sentido, este artigo tentou contribuir com a visibilização e relevância sócio-política das práticas de resistência das juventudes urbanas brasileiras, aquelas que junto ao movimento hip hop, vêm trabalhando e se construindo identitariamente a fim de denunciar desigualdades, violências e opressões e, produzir outros marcos de pensamento, sentimento, participação e comunicação.

Finalmente, consideramos que as práticas político-culturais das juventudes urbanas, aquelas nas quais os jovens se posicionam como autores de si mesmos, se apresentam como um campo interessante para continuar problematizando processos de resistência e transformação. Como questões a serem trabalhadas em pesquisas futuras sugerimos: a) abordagens interseccionais que aprofundem as relações entre raça, gênero e classe dentro do movimento hip hop; b) problematizações do hip hop na tensão entre "empreendedorismo cultural" e práticas micropolíticas; e c) perspectivas tecno-comunicacionais que abordem as potencialidades/limitações das mídias digitais como ferramentas de visibilidade, construção de redes e sustento econômico do movimento hip hop destes tempos.

\section{REFERÊNCIAS}

AMARAL, A. Indissociabilidade entre os mundos on e off-line. Entrevista concedida por Santos, João, V. Revista do Instituto Humanitas UNISINOS. Ed, 502, 10 abril 2017. Disponível: <http://www.ihuonline.unisinos.br/artigo/6813indissociabilidade-entre-os-mundos-on-e-off-line>. Acesso: 18 abril 2017. 
BRASIL. Estação juventude: conceitos fundamentais - ponto de partida para uma reflexão sobre políticas públicas de juventude/ organizado por Helena Abramo. Secretaria Nacional de Juventude (SNJ), Brasília, 2014.

BOGHOSSIAN, C. O.; MINAYO, M. C. de S. Revisão sistemática sobre juventude e participação nos últimos 10 anos. Saúde e sociedade, v. 18, n. 3, p. 411-423, 2009.

CANCLINI, N. G. Introducción. De la cultura postindustrial a las estrategias de los jóvenes. In: CANCLINI, N. G., CRUCES, F., POZO, M. U. C. Jóvenes, culturas urbanas y redes digitales. Madri: Ed. Ariel, Fundación Telefónica, 2012.

CARRANO, P. Políticas Públicas de Juventude: desafios da prática. In: JULIÃO, E. F.; VERGÍlIO, S. S. (Org.). Juventudes, Políticas Públicas e Medidas Socioeducativas, Rio de Janeiro: Novo Degase, 2013, pp. 17-36.

CASTRO, E. Vocabulário de Foucault: um percurso pelos seus temas, conceitos e autores. Belo Horizonte: Autêntica, 2009.

CURCINO, L; SARGENTINI, V. Presenças de Foucault na Análise do Discurso. São Carlos, SP: EdUFSCar, 2014.

CHARLOT, B. Da relação com o saber: elementos para uma teoria. Porto Alegre: Artemed, 2000.

D'ANDREA, T. P. A formação dos sujeitos periféricos: cultura e política na periferia de São Paulo. 2013. 295f. Tese (Sociologia) - Universidade de São Paulo, São Paulo/SP, 2013.

DAYRELL, J. O jovem como sujeito social. Juventude e Contemporaneidade. n. 24, pp. 40-52, 2003.

FELIX, J. B. J. Hip hop: cultura e política no contexto paulistano. 2005. $206 f$. Tese (Antropologia Social) - Universidade de São Paulo, São Paulo/SP, 2005.

FIRTH, S. Music for pleasure. Cambridge: Polity Press. 1988.

FONSECA, A. S. A. Versos violentamente pacíficos: o rap no currículo escolar. 201 1. 242f. Tese (Linguística Aplicada), Universidade Estadual de Campinas/SP, 2011

FOUCAULT, M. O que é um autor? In: MOTTA, M. B. Ditos e Escritos III. Estética: Literatura e Pintura, Música e Cinema. Rio de Janeiro, Forense Universitária, 2015.

FOUCAULT, M. A Arqueologia do Saber. Trad. Luiz Felipe Baeta Neves. 7ed. Rio de Janeiro: Forense Universitária, 2008.

GIROUX, H. Cruzando as fronteiras do discurso educacional: novas políticas em educação. Trad. Magda França Lopes. Porto Alegre: Artes Médicas Sul, 1999. 
GROPPO, L. A. Dialética das juventudes modernas e contemporâneas. Revista de Educação do COGEIME, v. 13, n. 25, p. 9-22, 2016.

HALL, S. Introduction and I. Representation, meaning and language. In: Representation: Cultural representations and signifying practices. Sage, 1997. pp. 01- 29.

HOLANDA, E. B. A política do hip hop nas favelas brasileiras. Alter/Nativas, revista de estudos culturais latino-americanos, n. 2, pp. 01-06, 2014.

LARROSA, J. 3. Tecnologias do ev e educação. In: SILVA, T. T. da (Org). 0 sujeito da educação. 2. ed. Petrópolis: Vozes, 1994. pp. 35-86.

MOZDZENSKI, L. As configurações genéricas e multimodais do videoclipe. Signo, v. 38, n. 64, p. 100-117, 2013.

OLIVEIRA, R. C. de. Rap e política: Percepções da vida social brasileira. São Paulo: Boitempo, 2015.

RIBEIRO, W. G. Currículo e hiphopologia: o que pensam pesquisadores brasileiros sobre Hip hop na escola? Conhecimento \& Diversidade, 2016, v. 8, n. 15, p. 72-83, 2016.

REGUILLO, R. Emergencia de culturas juveniles, estrategias del desencanto. Bogotá: Ed. Norma, 2000.

REGUILLO, R. Conferencia Rosana Reguillo 2018 - \# JóvenesfrentealaCrisis - R. Reguillo. II Jornadas sobre estudios de juventud. Respuestas juveniles a la crisis: innovación social, política, cooperación y acciones colectivas, Fuenlabrada, Espanha, 26janeiro 2018. YouTube. Disponível em: <https://www.youtube.com/watch? v=LAe57b7xdTA>. Acesso: 5 jul 2018.

REGUILLO, R. La Doctora Rossana Reguillo en la clausura del Encuentro Nacional "Jóvenes que investigan jóvenes" organizado por el Seminario de Investigación en Juventud UNAM, México D.F. México, 5 Março 2013. YouTube. Disponível em:

<https://www.youtube.com/watch?v=QtOmrlMqmCU>. Acesso:5 jul 2018.

ROGERS, R. The end of the virtual: Digital methods. Amsterdam: University Press, 2009.

SCOLARI, C. A. Alfabetismo transmedia. Estrategias de aprendizaje informal y competencias mediáticas en la nueva ecología de la comunicación. Revista Telos: Cuadernos de comunicación e innovación, n. 103, p. 12-23, 2016.

ZLUHAN, M. R.; RAITZ, T. R. Juventudes e as Múltiplas Maneiras de Ser Jovem na Atualidade. Revista de Ciências Humanas, v. 48, n. 2, p. 247-262, 2014.

Recebido em: 04 de outubro de 2018

Aprovado em: 15 de maio de 2019 